\title{
The effect of breakfast protein on appetite control in ageing subjects
}

\author{
E. O’Leary ${ }^{1}$, C. Fyfe ${ }^{2}$, W. Buosi ${ }^{2}$, D. Crabtree ${ }^{2}$, G. Horgan ${ }^{3}$ and A.M. Johnstone ${ }^{2}$ \\ ${ }^{1}$ University College Dublin, Belfield, Dublin 4, Ireland, \\ ${ }^{2}$ The Rowett Institute, University of Aberdeen, AB25 2ZD, UK and \\ ${ }^{3}$ Biomathematics and Statistics Scotland, Aberdeen, AB25 2ZD, UK
}

In 2025 , it is expected that more than 1.2 billion people worldwide will be aged $60+$ years. ${ }^{(1)}$ Adequate protein and energy intake is essential to the elderly as they are a group particularly vulnerable to malnutrition and unintentional weight loss. ${ }^{(1)}$ However, few studies directly assessed appetite control in this age group. At present the WHO has no specific recommendations in relation to dietary protein allowance for healthy older adults with current recommendations for healthy older adults, the same as younger adults $(0 \cdot 8 \mathrm{~g}$ protein $/ \mathrm{kg} /$ day). ${ }^{(2)}$ The aim of the current study was to assess appetite control in a group of lean volunteers in comparison to normal to overweight volunteers, all aged 65-75years old.

We recruited 50 volunteers in the Aberdeen area to participate in a dietary intervention, 23 as lean (16 F, 7M, BMI 18-22) and 27 as normal/overweight (13 F, 14M, BMI 22-27). Volunteers received two drinks, either (i) high protein or (ii) normal protein, presented in a randomised order on two separate days at breakfast time. The drinks were individually served in relation to energy requirements. On average they were provided as high protein (HP:high energy) containing $58 \mathrm{~g}$ and $65 \mathrm{~g}$ protein and $399 \mathrm{kcal}$ and $454 \mathrm{kcal}$ for the lean and normal weight volunteers, respectively. The normal protein (NP:lower energy) drink was diluted with water to contain a similar volume of drink. They provided $28 \mathrm{~g}$ and $32 \mathrm{~g}$ protein in $197 \mathrm{kcal}$ and $224 \mathrm{kcal}$ for the lean and normal weight volunteers, respectively. The volunteers recorded subjective appetite throughout the morning using visual analogue scales for 3 hours after consumption. A food diary was provided to record ad libitum intake for the rest of the day.

There were no differences between the lean and normal weight volunteers, with both groups reporting similar change in appetite sensations, nor were there any gender effects noted. On average, volunteers $(n=50)$ report feeling more hungry $(p<0 \cdot 001)$ and less full $(\mathrm{p}<0.001)$, with an elevated appetite score $(\mathrm{p}<0.001)$ after consuming the normal protein drink compared to the high protein drink. Therefore, these elderly volunteers were able to detect differences in appetite in response to a short-term morning meal manipulation. Interestingly, volunteers consumed a similar amount of food and energy for the rest of the day after the drink. On average, they consumed $1491 \mathrm{kcal}$ and $1476 \mathrm{kcal}$ after the HP and NP breakfast drinks. We did not find any gender effects, nor differences in calorie consumption between lean and normal/overweight volunteers.

Our data suggests that responsiveness to a protein and calorie load were similar between lean and normal to overweight volunteers, thus appetite control was not compromised by body mass/composition status. Our results also indicate that a breakfast time liquid protein drink did not compromise ad libitum intake later in the day. These data are useful to understand the role of protein amount, structure and timing of eating on prevention of sarcopenia associated with ageing.

The work is funded by the European Union Seventh Framework Programme (FP7/2007-2013) under grant agreement $n^{\circ} 266408$ for the "Full4Health" grant.

1. World Health Organisation (2002) Ageing and nutrition: a growing global challenge.

2. WORLD HEALTH ORGANIZATION (2007) Protein and amino acid requirements in human nutrition. Report of a joint FAO/WHO/UNU expert consultation (WHO Technical Report Series 935). Geneva, Switzerland: World Health Organization. 